\title{
A Vision for Drug Discovery and Development: Novel Targets and Multilateral Partnerships
}

\author{
Roger S. McIntyre
}

To view enhanced content go to www.advancesintherapy.com

Received: February 6, 2014 / Published online: March 4, 2014

(c) The Author(s) 2014. This article is published with open access at Springerlink.com

Dear Colleague,

Paradigm strain exists in psychiatric pharmacology. The prevailing monoaminebased psychotropic agents have in some circumstances saved lives, robustly benefitted patient reported outcomes (e.g., quality of life measures, functionality), and have facilitated reintegration and recovery. Unfortunately, these foregoing desirable outcomes are an uncommon occurrence for most individuals who receive existing treatments. For the common and severe brain disorders (e.g., mood, anxiety, and psychotic disorders), the insufficiency of extant treatments has provided the impetus to evaluate the role of other targets/systems. Moreover, there is consensus that available psychotropic agents are not "disease-modifing" and are rather symptom suppressing an/or providing only for temporary adaptation.

The paradigm strain of the monoamine hypotheses has resulted in a large number of

R. S. McIntyre ( $\square)$

Department of Psychiatry, University of Toronto, Toronto, Canada

e-mail: roger.mcintyre@uhn.ca antidepressants and antipsychotics that are not genuinely novel when compared to some of the erstwhile psychotropics (e.g., tricyclic antidepressants). It is however, incorrect to conclude that all antidepressants and antipsychotics are identical (they clearly are not), as evidenced by their tolerability, efficacy, and pharmacological profile. The business model in CNS therapeutics has fostered a level of complacency in drug discovery wherein, until recently, the return on investment has justified a maintenance of status quo.

The genericization of most psychotropic medicine, the "patent cliff" experienced by many blockbuster psychiatric medicines, and the lack of reimbursement by public/private payers has contributed to a lack of enthusiasm for drug development for psychiatric disorders. This foregoing confluence of factors could, however, provide the impetus for a different approach to drug discovery and development. Going forward, psychiatry, and its granting agencies, could do a much better job at instantiating viable clinical targets for psychiatric syndromes. Moreover, multilateral partnerships in other therapeutic areas (e.g., HIV-AIDS) have resulted in not only genuinely 
novel and revolutionary treatments, but treatments that are delivered in short time to the principal stakeholder, i.e., the patient.

During the next 1-2 years, psychiatry will continue to identify agents that are refinement and evolution of existing agents. In some cases, these agents may represent structural optimization from an existing progenitor molecule already in the clinical ecosystem. Contemporaneous with these foregoing developments are identification of agents with novel targets (e.g., intranasal ketamine, agents that target cellular bioenergetics/ inflammation). Moreover exploring the pluripotentiality of stem cells seems an exciting opportunity. Targeting many of the foregoing molecular systems is conveniently possible by repurposing some of the over 20,000 medicinal agents that are available globally. Examples of this have been observed in other therapeutic areas (e.g., the use of agents primarily intended for oncology to treat macular degeneration).

Where does that leave us? During the next 1-2 years, we will see new agents that have unique effects on monoaminergic systems (e.g., vortioxetine, levomilnacipran). The pursuit of mechanistically novel agents will be fuelled by scientific, clinical, economic, and health systems factors. It certainly has been identified that a yawning chasm exists between developments in neuroscience and genuinely novel "neuro-glial" pharmacology. It is unlikely that in 1-2 years the gap will witness a significant narrowing; it is, however, not unreasonable to expect the next 1-2 years to provide an empirical edifice for public, private, advocacy, and non-governmental organization support for unique psychotropic agents that are capable of modifying disease course.

I have found the developments in HIV-AIDS treatment to be the closest metaphor and inspiration for psychiatric therapeutics. On June 5, 1981, the first case of HIV-AIDS was identified in South Central Los Angeles. A year ago, the Centers for Disease Control and Prevention declared HIV-AIDS a chronic disease. This highly stigmatized condition which was a death sentence during the 1980s and 1990s, has witnessed such remarkable change in large part due to the openness to explore viable targets supported by multilateral partnership with an expectation of treatment availability in the very near future rather than some nebulous future date.

Psychiatry has not historically embraced multilateral partnerships-at its peril. The future, however, can look very bright if psychiatry embraces a multilateral pursuit of novel targets, provides bold leadership intellectually, and there is sufficient reward for sponsors who take the risk of investing in such pursuits.

Roger S. McIntyre

\section{CONFLICT OF INTEREST}

None.

Open Access. This article is distributed under the terms of the Creative Commons Attribution Noncommercial License which permits any noncommercial use, distribution, and reproduction in any medium, provided the original author(s) and the source are credited. 